\title{
Correction to: Classification of the human THAP protein family identifies an evolutionarily conserved coiled coil region
}

Hiral M. Sanghavi ${ }^{1}$, Sairam S. Mallajosyula ${ }^{2}$ and Sharmistha Majumdar ${ }^{1 *}$ (I)

\section{Correction to: BMC Struct Biol (2019) 19: 4 \\ https://doi.org/10.1186/s12900-019-0102-2}

In the publication of this article [1], there is an error for one of the contributing authors. This has now been updated in the original article [1].

The error:

Sairam S. Mallajosyala.

It should instead read:

Sairam S. Mallajosyula.

\section{Author details}

'Discipline of Biological Engineering, Indian Institute of Technology

Gandhinagar, Gandhinagar, India. ${ }^{2}$ Discipline of Chemistry, Indian Institute of

Technology Gandhinagar, Gandhinagar, India.

Received: 6 March 2019 Accepted: 6 March 2019

Published online: 29 March 2019

\section{Reference}

1. Sanghavi HM, Mallajosyula SS, Majumdar S. Classification of the human

THAP protein family identifies an evolutionarily conserved coiled coil region.

BMC Struct Biol. 2019;19(4). https://doi.org/10.1186/s12900-019-0102-2.

\footnotetext{
* Correspondence: sharmistham@iitgn.ac.in

'Discipline of Biological Engineering, Indian Institute of Technology

Gandhinagar, Gandhinagar, India
} 